\title{
DO WE ALL AGREE ON HOW TO MEASURE WORK ENGAGEMENT? FACTORIAL VALIDITY OF UTRECHT WORK ENGAGEMENT SCALE AS A STANDARD MEASUREMENT TOOL - A LITERATURE REVIEW
}

\section{KONRAD KULIKOWSKI}

\author{
Jagiellonian University, Kraków, Poland \\ Faculty of Philosophy, Institute of Psychology
}

\begin{abstract}
Work engagement as a predictor of health is an emerging concept in occupational science and the Utrecht Work Engagement Scale (UWES) is the most popular work engagement measurement tool. However, despite its popularity, the UWES is not free from controversy concerning its factorial validity. In this paper, 21 research studies on both UWES-9 and UWES-17 factorial validity within the confirmatory factor analysis (CFA) approach have been reviewed in order to answer the question as to which of the UWES factorial structures displays greater validity. The originally proposed threefactor structure of the UWES has been recognized as superior in 6 studies. In further 6 studies, the UWES structure with 1 general factor has been found to be superior. In 8 studies, the authors have concluded that the one- and three-factor structures could be considered equivalent. One study has failed to confirm either the one- or three-factor structure of the UWES. These ambiguous results from studies focusing on the UWES factorial validity are puzzling because they not only indicate a lack of validity for the UWES as a measurement tool but might also challenge the whole concept of work engagement as a three-factor structure of dedication, vigor and absorption. Int J Occup Med Environ Health 2017;30(2):161-175
\end{abstract}

Key words:

Measurements, Work engagement, Factorial validity, CFA, UWES, Utrecht Work Engagement Scale

\section{INTRODUCTION}

\section{Three-factorial model of work engagement}

Work engagement, as opposed to burnout, is an emerging concept in contemporary occupational health science and promotion of work engagement may lead to greater improvement in work performance than the traditional sole focus on disease prevention [1]. The concept of employee engagement represents a new approach to occupational health in which researchers are not only interested in what the causes of work related diseases are but also why people stay healthy and flourishing in a workplace [2].

There is a growing interest in work engagement research and an ongoing debate on how to define and measure it [3-6]. Recently, a three-factor model of work engagement, introduced by Schaufeli et al., [7] has become the most influential and most commonly used paradigm $[8,9]$.

Received: February 29, 2016. Accepted: August 11, 2016.

Corresponding author: K. Kulikowski, Jagiellonian University, Faculty of Philosophy, Institute of Psychology, Ingardena 6, 30-060 Kraków, Poland (e-mail: konrad.kulikowski@uj.edu.pl). 
Schaufeli et al. [7] define work engagement as "a positive work-related state of mind characterized by vigor, dedication and absorption. Rather than being conceived as a momentary and specific state, does engagement refer to a more persistent and pervasive affective - a cognitive state that is not focused on any particular object, event, individual or behavior. Vigor is characterized by high levels of energy and mental resilience while working, the willingness to invest effort in one's work, and persistence even in the face of difficulties. Dedication is characterized by a sense of significance, enthusiasm, inspiration, pride, and challenge. [...] The final dimension of engagement, absorption, is characterized by being fully concentrated and deeply engrossed in one's work, such time passes quickly and one has difficulties in detaching oneself from work" [7, p. 74-75]. In this approach [7] work engagement is a three-factor counterpart to burnout [10]. This notion of work engagement is operationalized in the Utrecht Work Engagement Scale (UWES) [7,11], a questionnaire which, according to the authors, captures the 3 different dimensions of engagement: vigor, absorption and dedication. Initially, Schaufeli and Bakker [11] introduced a questionnaire consisting of 17 items called the UWES-17, and then Schaufeli et al. [12] proposed a shortened version consisting of 9 items - UWES-9. Although the UWES-9 is much shorter, it explains about $80 \%$ of the variation in the UWES-17 [13] and is more stable over time [14]. Thus, nowadays, the UWES-9 is preferred over the UWES-17. There are other measures of work engagement in the literature [15-17] but the UWES is the most popular one and is treated as a standard measurement tool in work engagement research [18].

\section{Work engagement and health}

Research studies demonstrate that work engagement measured by the UWES is associated not only with superior work performance $[15,19,20]$ but also with the mental and physical health of employees.
Longitudinal studies among Dutch physiotherapists and students have shown that the UWES score is a predictor of long-term mental health [21]. Similar results have been obtained in a study on Dutch older employees (aged 45-64 years old) from a multi-occupational sample. Work engagement operationalized as the UWES score has been found to be a predictor of mental and physical health [22]. Among a multi-occupational sample of Japanese employees, the higher UWES score has been related to better health, higher job satisfaction and better job performance [23]. The UWES score has been also linked to the turnover in a sample of American nurses [24]. Dutch telecom managers with a higher score on the UWES have been characterized by better mental health and social functioning than their colleagues with the lower UWES score [25]. A 7-year longitudinal study has demonstrated that the UWES scores negatively predict depressive symptoms and positively predict overall life satisfaction [26]. A 2-year longitudinal study on Norway employees has shown that vigor, one of the 3 dimensions of engagement measured by the UWES, is a negative predictor of depression symptoms and anxiety [27]. Furthermore, the longitudinal study among telecom managers shows that work engagement predicts the frequency of absence due to illness but not the duration of sick leave [28]. Roelen et al. [29] suggest that the UWES may be used as a screening tool to detect employees who are at risk of long-term sick leave as a result of mental illness (an episode lasting $\geq 42$ consecutive days, caused by mental and behavioral disorders - ICD-10, chapter F [after: 29]); however, it is not a useful way to assess long-term sickness absence risk caused by somatic or musculoskeletal illness. In addition, work engagement as measured by the UWES was a predictor of work ability - the self-perceived capacity to fulfill the mental and physical demands of the job in a 6-month longitudinal study among employees from plastic and paint manufacture [30] as well as in a 10-year longitudinal study among Finnish firefighters [31]. 
Interestingly, work engagement measured by the UWES seems to be related not only to mental health but also to autonomic cardiac activity. Seppälä et al. [32], in a study on Finnish female cleaning workers, found evidence that work engagement was negatively related to heart rate and positively related to high-frequency power of heart rate variability. Authors concluded that "work engagement seems to be related to healthy, balanced, and adaptable autonomic cardiac activity" [32, p. 8].

Work engagement as measured by the UWES seems to have good predictive validity, but, despite its utility as demonstrated in empirical studies, the UWES is not completely free from controversy.

\section{Utrecht Work Engagement Scale issues}

Cole et al. [33] suggest that the UWES results simply reduplicate those of the Maslach Burnout Inventory (MBI), thus rendering this additional measurement tool redundant [34]. Critical comments have been voiced about the methodology used for developing the UWES [13]. The majority of questions within the UWES also seem to be similar or even identical to items from other wellknown measures of an employee's well-being, such as job satisfaction, positive affect or organizational commitment [35]. Rich et al. [36], based on Kahn's [37] work on the definition of engagement, point out that the questions used in the UWES confound work engagement precursors and work engagement itself.

Besides the above mentioned critique, the main problem with the UWES, as a contemporary standard work engagement measure, seems to be its factorial validity. The initial validation research conducted by the authors [7,11,12] in the confirmatory factor analysis (CFA) approach [38] revealed that the theoretical three-factor structure of the UWES fits the data better than the one-factor structure, but that the one-factor structure still fits the data in a reasonable way. So, ultimately, the authors were not able to reach a clear conclusion as to which structure: the one- or three-factor model is superior. Moreover, there were high and significant correlations between 3, theoretically separate, dimensions of work engagement. In data sets from 10 different countries, median correlations between 3 various dimensions were as follows: vigordedication $-r=0.95$, dedication-absorption $-r=0.92$, vigor-absorption $-r=0.9$ [12, p. 708]. In addition, some researchers have drawn attention to a lack of validity for the three-factor UWES $[16,39]$ or even state that neither the three-factor nor one-factor UWES is a valid measure of work engagement [17].

Taking all of the above into account, in this literature review, we aim to answer the question: what kind of the UWES factorial structure is the most valid one? This question might be important from both theoretical and practical perspectives, and could contribute to the overall development of an employee's well-being research. Despite the controversy, the UWES remains a standard measure used in most work engagement studies [8,18], and the majority of contemporary knowledge on work engagement is derived from studies based on the UWES results. Thus, establishing the most valid UWES factorial structure might be considered crucial for further development of work engagement research and could provide knowledge of the most valid means of measuring work engagement. To the best of our knowledge, this study is the first attempt to summarize all of the existing findings on the UWES factorial validity within the scope of a single analysis. As a consequence, it may help to clarify the understanding of the concept of work engagement and to develop best practices in work engagement measurement.

\section{MATERIAL AND METHODS}

The aim of the study is to explore the literature concerning the factorial validity of the UWES in order to answer the question: what kind of the UWES factorial structure might be considered the most valid one? For this purpose, we conducted a review of peer-reviewed scientific journals 
from the following online databases: EBSCO, Scopus, ResearchDirect and PubMed. In each database, we searched for combinations of the phrase: the Utrecht Work Engagement Scale; and each of words: validity, validation, factorial validity, psychometrics, dimensionality, properties, structure (e.g., the Utrecht Work Engagement Scale validity, Utrecht Work Engagement Scale validation, etc.); this resulted in 7 different sets of search key words. These sets of key words were searched for within: article titles, abstracts, article key words and article texts. Inclusion criteria for articles were as follows:

- written in English,

- published in a peer-reviewed journal,

- based on empirical findings,

- the tested UWES factorial validity in the confirmatory factor analysis (CFA) approach.

This search procedure uncovered 340 articles, and, after rejecting duplicates and articles not fulfilling the inclusion criteria, a final sample of 24 studies remained. Among those 24 studies, 3 of them represent the non-typical UWES-15 or 13 items configuration as being most valid; to avoid biases in the resulting interpretation, we have decided to omit these "outlier" studies from the review. This yields a final sample of 21 research studies.

\section{RESULTS}

The literature review has revealed 21 studies concerning the UWES factorial validity using the CFA approach. These studies were conducted in different organizational contexts, among employees from 24 different countries. Eleven studies investigated the UWES-9 alone, 1 study solely the UWES-17, and 9 studies compared the factorial validity of both UWES-9 and UWES-17. Detailed descriptions of each report, and conclusions made by the author(s) of each study about the UWES factorial structure are presented in the Table 1. It is worth noting that there is a lack of literature concerning the UWES factorial validity among employees from Eastern European countries.
As we can see in the Table 1, among studies investigating the UWES- 9 alone, 3 studies have confirmed the onefactor structure, 3 studies have supported the three-factor structure, in 4 studies the authors have considered oneand three-factor structures as equivalent, and 1 study has failed to support both one- and three-factor structures. One study has focused solely on the UWES-17 factorial validity and has preferred the three-factor configuration as slightly better than one-factor. Research studies comparing the validity of the UWES-17 and UWES-9 have revealed that, regardless of the proposed factorial structure, in 8 out of 9 studies, the UWES-9 had been found to be psychometrically better than the UWES-17, and in 1 study the UWES-9 had been assessed as equivalent to the UWES-17. When it comes to the factorial structure, among studies comparing both the UWES-17 and UWES9, only 1 study has found a different factorial structure for the UWES-9 (one-factor) and the UWES-17 (two-factor), while in the remaining 8 studies the same factorial structure has been found for both UWES-9 and UWES-17. Two studies have endorsed the one-factor structure, 2 studies the three-factor structure, and 4 studies have proposed that both one- and three-factor structures may be regarded as equivalent and valid.

Generally, among studies regarding the UWES-9 and UWES-17, the originally proposed three-factor structure of the UWES [7,12] was recognized as superior to the one-factor structure in 6 out of the 21 studies. In 6 reports, the UWES structure with 1 general factor was found to be superior to the three-factor structure. Additionally, in 8 studies the authors concluded that one- and three-factor structures could be considered equivalent and could be used by researchers interchangeably. Finally, 1 study [17] failed to confirm either the one- or a three-factor structure for the UWES, and the authors have concluded that this method of measuring work engagement may be inherently flawed. Researchers seem to agree that the UWES-9 is not dissimilar to the UWES-17 but is a parsimonious version of 


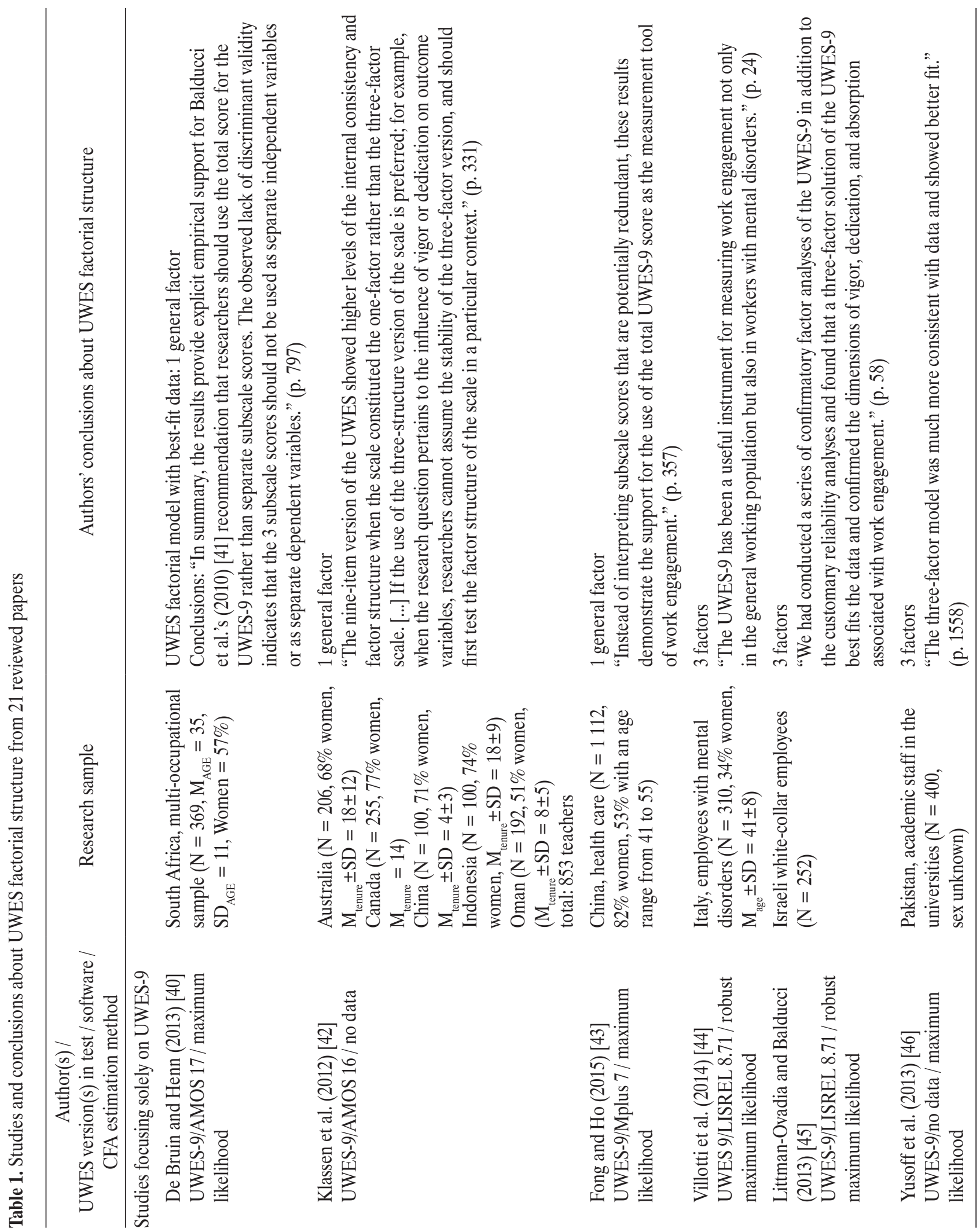




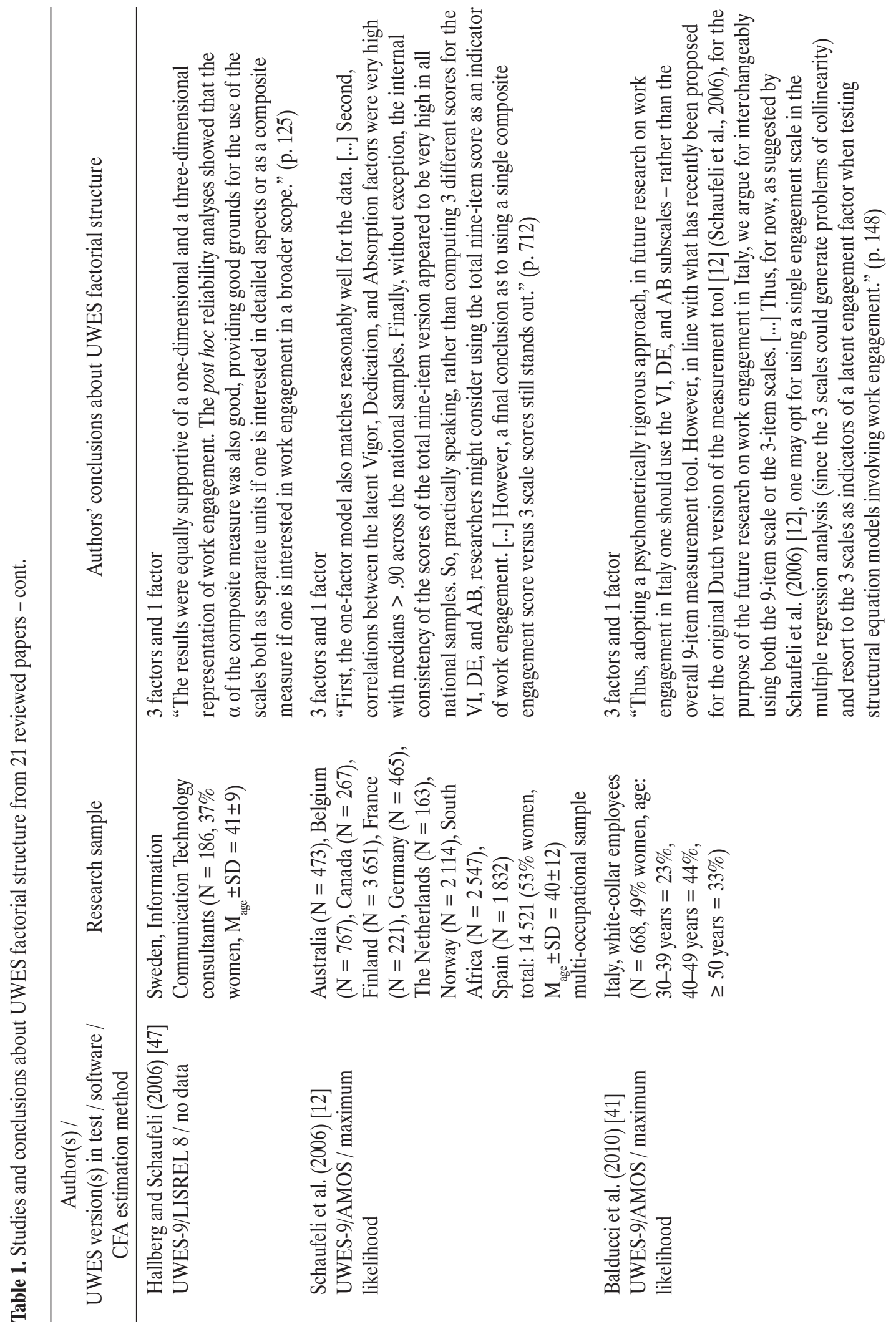




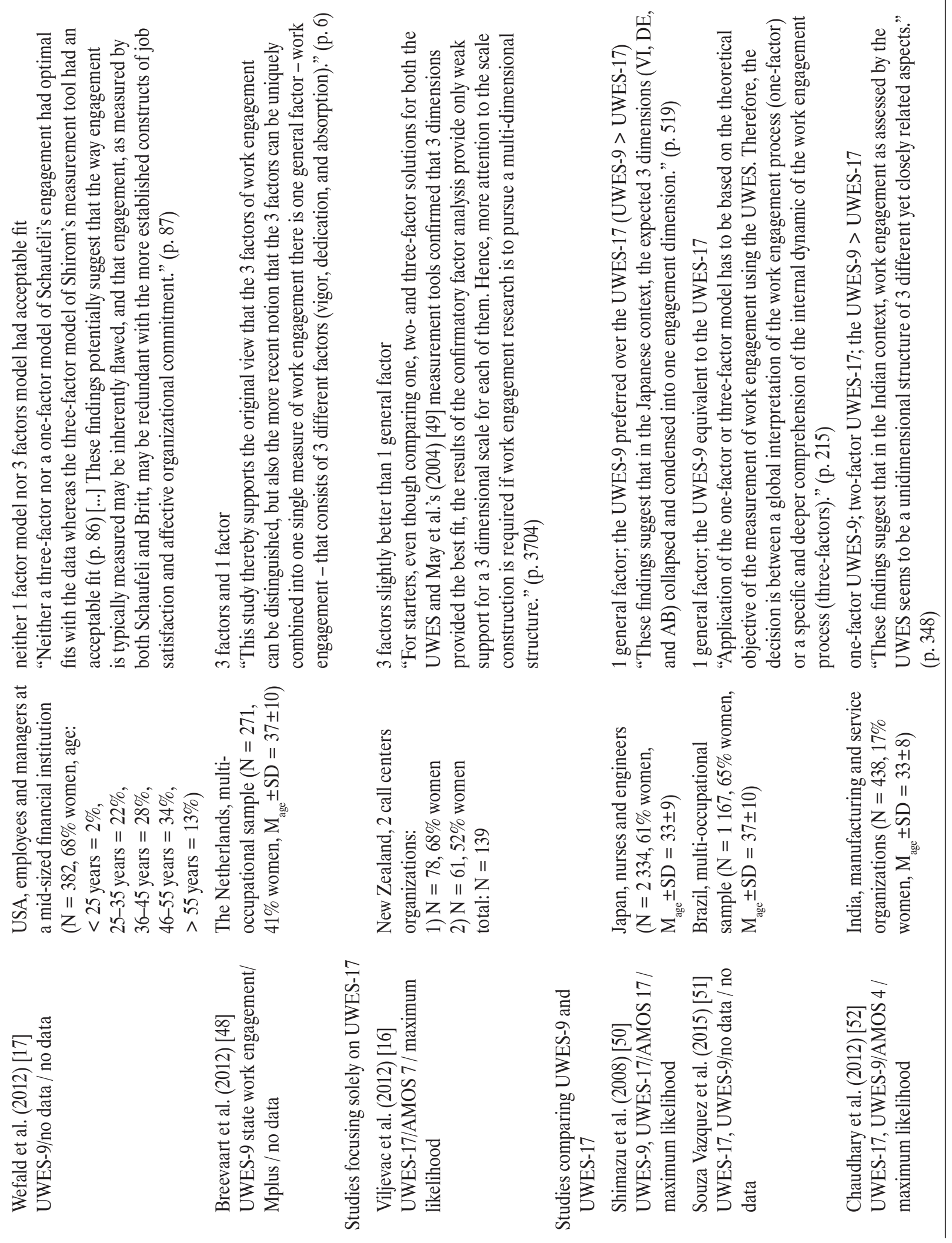




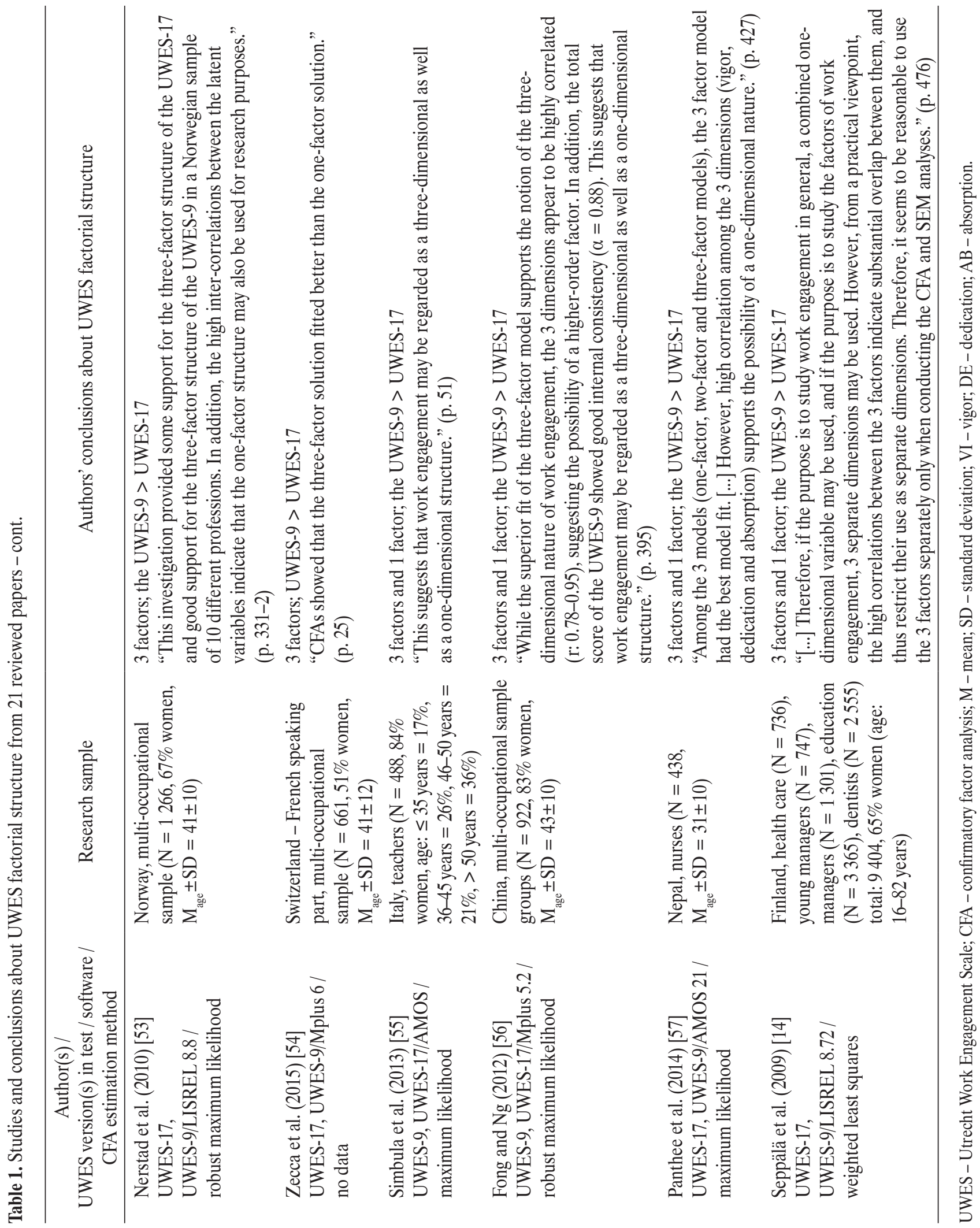


the UWES-17. Moreover, in 8 out of 9 analyses comparing the UWES-9 to UWES-17, the same factorial structure for both versions was found; there were differences in the factor structure between the studies but not within studies. As the UWES-9 is not a different measurement tool but simply a shortened version of the UWES-17 with similar or better psychometric properties, in the next section we discuss the issues concerning the UWES as a single measurement tool.

The authors identify a superior validity for the one-factor structure over the three-factor structure of the UWES, drawing attention to the very high correlations between the 3 , theoretically separated, subscales of vigor, dedication and absorption [51,52]. They proceed to highlight the fact that we can use the dedication score in place of the one for vigor or absorption without any substantial loss of information [40]. Other authors have also stressed the higher stability of the one-factor over the three-factor structure when tested in various groups of employees [42,50]. Additionally, 1 study [40] underlines the lack of discriminant validity of these separate dimensions: vigor, dedication and absorption.

There is some evidence that the one-factor structure might be more valid than the three-factor one. However, as can be seen in the Table 1, some authors find the higher factorial validity for the three-factor structure of the UWES and opt for using separate scores for vigor, dedication, and absorption instead of one general work engagement score [44-46,54].

The three-factor structure of the UWES has shown stability across 10 Norwegian occupational samples [53], which may constitute strong evidence of its validity. There are also some studies in which the three-factor structure is considered more valid than the one-factor structure, despite not being the optimal one $[13,16]$.

There are studies (Table 1), the findings of which do not give a clear answer for the UWES factorial structure, stating that both the one- and three-factor structure may be considered as being equally valid. For example,
Schaufeli et al. [12] have generally approved of the threefactor structure of the UWES but propose the possible use a total of the UWES scores as an indicator of work engagement in practice. There is also the suggestion that if researchers are keen to analyze detailed aspects of work engagement, they might prefer to use the three-factor approach, but if interest lies only in work engagement in general, then, they could choose to use the one-factor structure [47]. Other authors [12,41] suggest that the use of a particular UWES factorial structure may depend on the preferred statistical analysis methods of the researcher; if a study wishes to use work engagement in multiple regression, then, to avoid the problem of collinearity of 3 highly correlated dimensions, the one-factor structure engagement scale might be used. Conversely, if a researcher wants to create structural equation models (SEM) with work engagement as a latent variable, then 3 subscales might serve as 3 separate but highly correlated indicators of work engagement. Seppälä et al. [14] even suggest that the use of a three-factor structure is reasonable only in scientific studies using SEM or CFA, but in any practical application, the one-factor model should be preferred.

\section{DISCUSSION}

The main aim of this study has been to explore the existing literature concerning the UWES factorial validity and answer the question: what kind of the UWES factorial structure is the most valid one? Based on the literature review, we have found ambiguous results and thus, we have not been able to definitively resolve the issue of the most valid UWES factorial structure. There is no common agreement on the UWES factorial structure, but it is still one of the most commonly used work engagement measures and it is applied almost invariably as a standard measurement tool in work engagement research. This leads us to the conclusion that using the three-factor UWES as a standard work engagement measure might be questionable. To address this, we have proposed some ideas that 
might help improve future findings from studies on work engagement.

Firstly, as almost all of the studies comparing the UWES-9 and UWES-17 preferred the UWES-9 as a more valid and reliable measure of work engagement (Table 1), it might thus be preferable to use the UWES-9 in place of the UWES-17 in any particular research.

Secondly, since the three-factor structure of the UWES is clearly more complex than the one-factor structure, it is advisable that the former be preferred only if it offers additional information as compared to the simpler one-factor structure. But the 3 theoretically separated UWES factors are closely related [12], and there seems to be a lack of discriminant validity for separate usage of vigor, dedication and absorption [40]. Moreover, as the current review has shown, there is only limited evidence supporting the factorial validity of a three-factor structure over a one-factor structure among studies on the UWES factorial validity. The majority of authors conclude (Table 1) that from a practical point of view, it is more reasonable to measure and interpret work engagement as a homogeneous construct, represented by 1 general factor. Therefore, it seems rational to assume that little is to be gained by splitting the UWES into 3 separate subscales because it might merely offer an illusion of additional information [58]. In a practical application it might be more reasonable to set a standard of treating work engagement as a simple one-dimensional structure. The three-factor structure of the UWES was confirmed in some research studies and cannot be simply ruled out; however, more research studies are needed to test what additional information we might gain when we use vigor, dedication and absorption instead of simply the total of the UWES score.

Thirdly, the inconclusive results of studies concerning the UWES factorial structure indicate the importance of routinely testing and reporting the UWES factorial validity in research on employee engagement. Introducing a standard of reporting the CFA results of the UWES factorial structure in each research study on work engagement may contribute to further development in related research, rather than simply referring to literature which has shown the validity of the UWES factorial structure chosen in advance. This is because, based on the literature, researchers can support the three- or one- structure of the UWES at their sole discretion, simply by referring to selected papers from those extant in the literature (Table 1). Therefore, a good practice in research studies to the extent of the UWES might be to routinely support the UWES factorial structure as indicated by the CFA results. Clearly, in some cases, using groups large enough to conduct the CFA might be unfeasible; in such situations the UWES-9 should be implemented and interpreted as a unidimensional structure. Based on the results of this review, it seems reasonable to assume that the UWES-9 has better psychometric properties than the UWES-17. Moreover, as long as the UWES multidimensional structure cannot be proven in terms of the CFA, it seems more reasonable to assume that the UWES has the one-factor structure.

Fourthly, the important question that has arisen from this literature review is why there is such inconsistency between studies on the UWES factorial structure. Is it due to methodological issues such as translation problems, research groups of too small a size, or other biases that may affect the questionnaire measurement? Based on the articles included in this review, it seems that there is no justifiable reason to assign the lack of the UWES factor stability to methodological issues since the studies included in the review were conducted with the appropriate methodological rigor. Additionally, the instability of the UWES cannot be assigned to the research group composition due to the fact that structural factors vary across groups of similar size, sex, occupation, and even within the same countries. However, in looking at this UWES factorial inconsistency, we would like to point out one possible explanation that, from our perspective, is missing in the literature on work engagement. We hypothesize that work engagement might 
not be a universally invariant phenomenon but it rather might be specific to particular work contexts. Thus, in different contexts, the UWES yields different factorial structures, which simply reflects different types of engagement. Different work contexts arise from diverse organizational cultures, variegated work ethics, and economic backgrounds, and these might influence the structure of work engagement. It is likely that work engagement tends to have differing dimensions, e.g., among Israeli white-collar workers or Japanese nurses. Thus, in further analyses, we would do well to focus on analyses of how measurement contexts may influence the UWES factorial structure.

\section{CONCLUSIONS}

There is no doubt that research studies based on the UWES have made a tremendous contribution to our current understanding of human health and performance in the workplace. However, based on the literature review conducted in this paper, we might conclude that the three-factor structure of the most popular work engagement measure, the UWES, is not invariant across different measurement contexts, and the results of the UWES factorial validation studies are inconclusive.

The ambiguous results of studies concerning the UWES factorial validity are puzzling, because they not only indicate a lack of validity for the UWES as a measurement tool but might also challenge the whole concept of work engagement as the three-factor structure of dedication, vigor and absorption. In the light of this literature review, we might state that, while the unidimensional UWES-9 total score could be used in practical applications, it might be generally inadvisable to divide the UWES into 3 separate dimensions. The UWES-9 total score itself is quite easy to interpret, has a good predictive validity for health and well-being, and it is nested in an extended nomological net in the framework of the Job Demand-Resources theory [59]. In contrast, the multifactorial structure of the UWES varies across studies and might give us only an illusion of additional information [58].
This review indicates that, despite its popularity, the UWES is not an ideal tool for work engagement measurement. The notion of the three-factor work engagement and its operationalization through the UWES is popular and widely used; however, the results presented here suggest that it is far from perfect, and that the question of how to (properly) measure work engagement is still an open one. In our estimation, instead of relying on the automatic usage of the three-factor UWES as a standard, it would be preferable for researchers to expend further effort to seek a more valid and invariant measure of work engagement $[49,60,61]$. A good example of a fruitful and novel approach to the reconceptualization of work engagement is the attempt of Matz-Costa et al. [62]. The authors treat work engagement as a unidimensional structure characterized by high energy, focus, and interest in the work role. Based on this conceptualization, and supported by a 4th facet of engagement - perseveration, Ludlow et al. [63] have developed the Productive Engagement Portfolio scenario scales. The questionnaire is based on the Item Response Theory, and it uses scenarios as items instead of the Likert type scale. Ludlow et al. [63] have shown that using specific scenarios describing hypothetical people and situations, and asking participants to relate to these scenarios, might yield fertile results when dealing with the complicated and ambiguous concept of work engagement. This scenario scales approach has been already successfully applied to a sample of older adults; however, further research is needed to confirm its validity for the general population, especially young and mid-life adults.

To summarize, it seems viable to continue to employ the one-factor UWES-9 as an imperfect but well-known measurement tool since being more cognizant of the drawbacks in the use of UWES means we are in a better position to take them into account; this is in contrast to other novel approaches, the validity of which has not yet been fully explored. Notwithstanding, we cannot desist from a search for better work engagement measures than the current UWES questionnaire. 


\section{ACKNOWLEDGMENTS}

I would like to thank the 2 anonymous Reviewers for their constructive and insightful comments which have helped me to improve the manuscript.

\section{REFERENCES}

1. Torp S, Grimsmo A, Hagen S, Duran A, Gudbergsson SB. Work engagement: A practical measure for workplace health promotion. Health Promot Int. 2012;28(3):387-96, https:// doi.org/10.1093/heapro/das022.

2. Diener E, Wirtz D, Tov W, Kim-Prieto C, Choi D, Oishi S, et al. New well-being measures: Short scales to assess flourishing and positive and negative feelings. Soc Indic Res. 2010;97(2): 143-56, https://doi.org/10.1007/s11205-009-9493-y.

3. Simpson MR. Engagement at work: A review of the literature. Int J Nurs Stud. 2009;46(7):1012-24, https://doi.org/10.1016/ j.ijnurstu.2008.05.003.

4. Bakker AB, Albrecht SL, Leiter MP. Work engagement: Further reflections on the state of play. Eur J Work Organ Psychol. 2011;20(1):74-88, https://doi.org/10.1080/1359432X. 2010.546711.

5. Jeung C-W. The concept of employee engagement: A comprehensive review from a positive organizational behavior perspective. Perform Improv Q. 2011;24(2):49-69, https://doi. org/10.1002/piq.20110.

6. Shuck B, Ghosh R, Zigarmi D, Nimon K. The jingle jangle of employee engagement: Further exploration of the emerging construct and implications for workplace learning and performance. Hum Resour Dev Rev. 2012;12(1):11-35, https://doi.org/10.1177/1534484312463921.

7. Schaufeli WB, Salanova M, González-Romá V, Bakker AB. The measurement of engagement and burnout: A two sample confirmatory factor analytic approach. J Happiness Study. 2002;3:71-92, https://doi.org/10.1023/A:1015630930326.

8. Shuck B. Integrative literature review: Four emerging perspectives of employee engagement: An integrative literature review. Hum Resour Dev Rev. 2011;10(3):304-28, https://doi. org/10.1177/1534484311410840.
9. Schaufeli W, Salanova M. Work engagement: On how to better catch a slippery concept. Eur J Work Organ Psychol. 2011;20(1):39-46, https://doi.org/10.1080/1359432X. 2010.515981.

10. Bakker AB, Schaufeli WB. Positive organizational behavior: Engaged employees in flourishing organizations. J Organ Behav. 2008;29:147-54, https://doi.org/10.1002/job.515.

11. Schaufeli WB, Bakker AB. Utrecht Work Engagement Scale. Preliminary manual. Utrecht: Utrecht University; 2003.

12. Schaufeli WB, Bakker AB, Salanova M. The measurement of work engagement with a short questionnaire: A cross-national study. Educ Psychol Meas. 2006;66(4):701-16, https:// doi.org/10.1177/0013164405282471.

13. Mills MJ, Culbertson SS, Fullagar CJ. Conceptualizing and measuring engagement: An analysis of the Utrecht Work Engagement Scale. J Happiness Study. 2012;13(3):519-45, https://doi.org/10.1007/s10902-011-9277-3.

14. Seppälä P, Mauno S, Feldt T, Hakanen J, Kinnunen U, Tolvanen A, et al. The construct validity of the Utrecht Work Engagement Scale: Multisample and longitudinal evidence. J Happiness Stud. 2009;10(4):459-81, https://doi.org/ 10.1007/s10902-008-9100-y.

15. Christian MS, Garza AS, Slaughter JE. Work engagement: A quantitative review and test of its relations with task and contextual performance. Pers Psychol. 2011;64(1):89-136, https://doi.org/10.1111/j.1744-6570.2010.01203.x.

16. Viljevac A, Cooper-Thomas HD, Saks AM. An investigation into the validity of 2 measures of work engagement. Int J Hum Resour Manage. 2012;23:3692-709, https://doi.org/ 10.1080/09585192.2011.639542.

17. Wefald AJ, Mills MJ, Smith MR, Downey RG. A comparison of three job engagement measures: Examining their factorial and criterion-related validity. Appl Psychol Health Well Being. 2012;4(1):67-90, https://doi.org/10.1111/j.1758-0854. 2011.01059.x.

18. Saks AM, Gruman JA. What do we really know about employee engagement? Hum Resour Dev Q. 2014;25(2):155-82, https://doi.org/10.1002/hrdq.21187. 
19. Bakker AB, Bal MP. Weekly work engagement and performance: A study among starting teachers. J Occup Organ Psychol. 2010;83(1):189-206, https://doi.org/10.1348/09631 7909 X402596.

20. Shimazu A, Schaufeli WB, Kamiyama K, Kawakami N. Workaholism vs. work engagement: The two different predictors of future well-being and performance. Int J Behav Med. 2015;22(1):18-23, https://doi.org/10.1007/s12529-0149410-X.

21. Reis D, Hoppe A, Schröder A. Reciprocal relationships between resources, work and study engagement, and mental health: Evidence for gain cycles. Eur J Work Organ Psychol. 2015;24(1):1-17, https://doi.org/10.1080/1359432x. 2013.834891.

22. Leijten FRM, van den Heuvel SG, van der Beek AJ, Ybema JF, Robroek SJW, Burdorf A. Associations of work-related factors and work engagement with mental and physical health: A 1-year follow-up study among older workers. J Occup Rehabil. 2015;25(1):86-95, https://doi.org/10.1007/ s10926-014-9525-6.

23. Shimazu A, Schaufeli WB, Kubota K, Kawakami N. Do workaholism and work engagement predict employee wellbeing and performance in opposite directions? Ind Health. 2012;50(4):316-21, https://doi.org/10.2486/indhealth.MS1355.

24. Collini SA, Guidroz AM, Perez LM. Turnover in health care: The mediating effects of employee engagement. J Nurs Manag. 2015;23(2):169-78, https://doi.org/10.1111/jonm.12109.

25. Schaufeli WB, Taris TW, van Rhenen W. Workaholism, burnout and engagement 3 of a kind or 3 different kinds of employee well-being. Appl Psychol. 2008;57:173-203, https:// doi.org/10.1111/j.1464-0597.2007.00285.x.

26. Hakanen JJ, Schaufeli WB. Do burnout and work engagement predict depressive symptoms and life satisfaction? A three-wave seven-year prospective study. J Affect Disord. 2012;141(2-3):415-24, https://doi.org/10.1016/j.jad. 2012.02.043.

27. Innstrand ST, Langballe EM, Falkun E. A longitudinal study of the relationship between work engagement and symp- toms of anxiety and depression. Stress Health. 2012;28:1-10, https://doi.org/10.1002/smi.1395.

28. Schaufeli WB, Bakker AB, van Rhenen W. How changes in job demands and resources predict burnout, work engagement, and sickness absenteeism. J Organ Behav. 2009; 30:893-917, https://doi.org/10.1002/job.595.

29. Roelen CAM, van Hoffen MFA, Groothoff JW, de Bruin J, Schaufeli WB, van Rhenen W. Can the Maslach Burnout Inventory and Utrecht Work Engagement Scale be used to screen for risk of long-term sickness absence? Int Arch Occup Environ Health. 2014;88(4):467-75, https://doi.org/ 10.1007/s00420-014-0981-2.

30. Rongen A, Robroek SJ, Schaufeli W, Burdorf A. The contribution of work engagement to self-perceived health, work ability, and sickness absence beyond health behaviors and work-related factors. J Occup Environ Med. 2014;56(8): 892-7, https://doi.org/10.1097/JOM.0000000000000196.

31. Airila A, Hakanen JJ, Punakallio A, Lusa S, Luukkonen R. Is work engagement related to work ability beyond working conditions and lifestyle factors? Int Arch Occup Environ Health. 2012;85(8):915-25, https://doi.org/10.1007/s00420012-0732-1.

32. Seppälä P, Mauno S, Kinnunen M, Feldt T, Juuti T, Tolvanen A, et al. Is work engagement related to healthy cardiac autonomic activity? Evidence from a field study among Finnish women workers. J Posit Psychol. 2012;7:95-106, https://doi.org/10.1080/17439760.2011.637342.

33. Cole MS, Walter F, Bedeian AG, O'Boyle EH. Job burnout and employee engagement: A meta-analytic examination of construct proliferation. J Manage. 2012;38:1550-81, https:// doi.org/10.1177/0149206311415252.

34. Maslach C, Jackson SE, Leiter MP. Maslach Burnout Inventory manual. 3rd ed. Palo Alto: Consulting Psychologists Press; 1996.

35. Newman DA, Harrison DA. Been there, bottled that: Are state and behavioral work engagement new and useful construct "wines"? Ind Organ Psychol. 2008;1(1):31-5, https:// doi.org/10.1111/j.1754-9434.2007.00003.x. 
36. Rich BL, Lepine JA, Crawford ER. Job engagement: Antecedents and effects on job performance. Acad Manage J. 2010;53(3):617-35, https://doi.org/10.5465/AMJ. 2010.51468988.

37. Kahn WA. Psychological condition of personal engagement and disengagement at work. Acad Manage J. 1990;33(4): 692-724, https://doi.org/10.2307/256287.

38. Schreiber JB, Nora A, Stage FK, Barlow EA, King J. Reporting structural equation modeling and confirmatory factor analysis results: A review. J Educ Res. 2006;99(6):323-38, https://doi.org/10.3200/JOER.99.6.323-338.

39. Sonnentag S. Recovery, work engagement, and proactive behavior: A new look at the interface between nonwork and work. J Appl Psychol. 2003;88:518-28, https://doi. org/10.1037/0021-9010.88.3.518.

40. De Bruin GP, Henn CM. Dimensionality of the 9-item Utrecht Work Engagement Scale (UWES-9). Psychol Rep. 2013;112(3):788-99, https://doi.org/10.2466/01.03.PR0. 112.3.788-799.

41. Balducci C, Fraccaroli F, Schaufeli WB. Psychometric properties of the Italian version of the Utrecht Work Engagement Scale (UWES-9): A cross-cultural analysis. Eur J Psychol Assess. 2010;26(2):143-9, https://doi.org/10.1027/10155759/a000020.

42. Klassen RM, Aldhafri S, Mansfield CF, Purwanto E, Siu AFY, Wong MW, et al. Teachers' engagement at work: An international validation study. J Exp Educ. 2012;80(4): 317-37, https://doi.org/10.1080/00220973.2012.678409.

43. Fong TC, Ho RTH. Dimensionality of the 9-item Utrecht Work Engagement Scale revisited: A Bayesian structural equation modeling approach. J Occup Health Psychol. 2015;1(2):353-8, https://doi.org/10.1539/joh.15-0057-OA.

44. Villotti P, Balducci C, Zaniboni S, Corbiere M, Fraccaroli F. An analysis of work engagement among workers with mental disorders recently integrated to work. J Career Assess. 2014;22(1):18-27, https://doi.org/10.1177/1069072713487500.

45. Littman-Ovadia H, Balducci C. Psychometric properties of the Hebrew version of the Utrecht Work Engagement Scale
(UWES-9). Eur J Psychol Assess. 2013;29:58-63, https://doi. org/10.1027/1015-5759/a000121.

46. Yusoff RBM, Ali AM, Khan A, Bakar SA. Psychometric evaluation of Utrecht Work Engagement Scale among academic staff in universities of Pakistan. World Appl Sci J. 2013;28(11):1555-60.

47. Hallberg UE, Schaufeli WB. "Same same" but different? Can work engagement be discriminated from job involvement and organizational commitment? Eur Psychol. 2006;11(2):119-27, https://doi.org/10.1027/1016-9040. 11.2.119.

48. Breevaart K, Bakker AB, Demerouti E, Hetland J. The measurement of state work engagement. A multilevel factor analytic study. Eur J Psychol Assess. 2012;28(4):305-12, https:// doi.org/10.1027/1015-5759/a000111.

49. May DR, Gilson RL, Harter LM. The psychological conditions of meaningfulness, safety and availability and the engagement of the human spirit at work. J Occup Organ Psychol. 2004;77(1):11-37, https://doi.org/10.1348/09631790432 2915892.

50. Shimazu A, Schaufeli WB, Kosugi S, Suzuki A, Nashiwa H, Kato A, et al. Work engagement in Japan: Validation of the Japanese version of The Utrecht Work Engagement Scale. Appl Psychol. 2008;57(3):510-23, https://doi.org/10.1111/ j.1464-0597.2008.00333.x.

51. Souza Vazquez AC, dos Santos Magnan E, Cerentini Pacico J, Hutz CS, Schaufeli WB. Adaptation and validation of the Brazilian version of the Utrecht Work Engagement Scale. Psico-USF. 2015;20(2):207-17, https://doi.org/ 10.1590/1413-82712015200202.

52. Chaudhary R, Rangnekar S, Barua MK. Psychometric evaluation of Utrecht Work Engagement Scale in an Indian sample. Asia Pac J Manage Res Innov. 2012;8(3):343-50, https:// doi.org/10.1177/2319510x1200800314.

53. Nerstad CGL, Richardsen AM, Martinussen M. Factorial validity of the Utrecht Work Engagement Scale (UWES) across occupational groups in Norway. Scand J Psychol. 2010;51(4):326-33. 
54. Zecca G, Györkös C, Becker J, Massoudi K, de Bruin GP, Rossier J. Validation of the French Utrecht Work Engagement Scale and its relationship with personality traits and impulsivity. Eur Rev Appl Psychol. 2015;65(1):19-28, https:// doi.org/10.1016/j.erap.2014.10.003.

55. Simbula S, Guguelmi D, Schaufeli WB, Depolo M. An Italian validation of the Utrecht Work Engagement Scale: Characterization of engaged groups in a sample of schoolteachers. Appl Psychol Bull. 2013;61(268):43-54.

56. Fong TC, Ng SM. Measuring engagement at work: Validation of the Chinese version of the Utrecht Work Engagement Scale. Int J Behav Med. 2012;19(3):391-7, https://doi. org/10.1007/s12529-011-9173-6.

57. Panthee B, Shimazu A, Kawakami N. Validation of Nepalese version of Utrecht Work Engagement Scale. J Occup Health. 2014;56(6):421-9, https://doi.org/10.1539/joh.14-0041-OA.

58. De Bruin DP, Hill C, Henn CM, Muller K-P. Dimensionality of the UWES-17: An item response modelling analysis. SA J Ind Psychol. 2013;39(2):1-8, https://doi.org/10.4102/sajip. v39i2.1148.
59. Demerouti E, Bakker AB. The Job Demands-Resources model: Challenges for future research. SA J Ind Psychol. 2011;37(2):1-9, https://doi.org/10.4102/sajip.v37i2.974.

60. Britt TW, Castro CA, Adler AB. Self-engagement, stressors, and health: A longitudinal study. Pers Soc Psychol Bull. 2005;31(11):1475-86, https://doi.org/10.1177/01461672 05276525 .

61. Shraga O, Shirom A. The construct validity of vigor and its antecedents: A qualitative study. Hum Relat. 2009;62(2): 271-91, https://doi.org/10.1177/0018726708100360.

62. Matz-Costa C, James JB, Ludlow L, Brown M, Besen E, Johnson C. The meaning and measurement of productive engagement in later life. Soc Indic Res. 2014;118(3): 1293-314, https://doi.org/10.1007/s11205-013-0469-6.

63. Ludlow L, Matz-Costa C, Johnson C, Brown M, Besen E, James JB. Measuring engagement in later life activities: Rasch-based scenario scales for work, caregiving, informal helping, and volunteering. Meas Eval Couns Dev. 2014;47(2): 127-49, https://doi.org/10.1177/0748175614522273.

This work is available in Open Access model and licensed under a Creative Commons Attribution-NonCommercial 3.0 Poland License - http://creativecommons.org/ licenses/by-nc/3.0/pl/deed.en. 